\title{
Green Technology for Eco-friendly and Sustainable Shipping using Adjustable Speed Drive
}

\author{
Mr. Sanjay Dabadgaonkar ${ }^{1}$, Dr. Asim Kumar Sen ${ }^{2}$, Dr. Rajendra Prasad ${ }^{3}$ \\ Fellow (IEI), Sr. Associate Prof. (Electrical \& Electronics), Tolani Maritime Institute, Induri, Pune ${ }^{1}$ \\ Fellow (IEI), Principal, St. Francis Institute of Technology, Mount Poinsur, Borivali (West), Mumbai ${ }^{2}$ \\ Professor (Marine Engineering), Tolani Maritime Institute, Induri, Pune ${ }^{3}$
}

\begin{abstract}
The revised MARPOL Convention adresses émissions from ships under Annex VI, chapter 4, entered into force since $1^{\text {st }}$ January 2013. It set mandatory measures to reduce emissions of greenhouse gases (GHGs) from international shipping, with the Energy Efficiency Design Index (EEDI) made mandatory for new ships, and the Ship Energy Efficiency Management Plan (SEEMP) made a requirement for all ships. The major consumption of energy and burning of fuel onboard is generally required for Ballast water management, Sea water cooling, Cargo operation and Propulsion. Energy efficiency plays the most important role in reduction of energy consumption, fuel consumption and $\mathrm{CO}_{2}$ emissions, accounting for up to $53 \%$ of total $\mathrm{CO}_{2}$ emission reductions onboard ship. In pumping applications onboard vessels for sea water cooling systems, the use of proposed Variable Frequency Drives (VFD) control can cut the energy consumption by as much as $60 \%$. Here we have developed a model of adjustable speed drives for controlling high power centrifugal pumps onboard ship for energy conservation and eco-friendly sailing. The results of simulation shows that the proposed method of flow control using VFD not only saves energy but also reduces burning of fuel and also results in a reduction of greenhouse gas emission. Therefore by the use of proposed Green, Smart and Intelligent technology, we can save significant energy and reduce emission of GHG, so as to meet stringent norms as per MARPOL ANNEX-VI, Chapter-4.
\end{abstract}

Keywords: MARPOL, Centrifugal Pump, Sea Water Cooling, Ballast Water Management, Three Phase Inverter, SVPWM, Variable Frequency Drive, Green Technology and Energy Saving.

\section{INTRODUCTION}

Shipping is truly the backbone of the international economy. It significantly contributes to international trade and the world economy as the most efficient, safe and environmentally friendly method of transporting goods around the globe. Therefore without shipping, intercontinental trade, the bulk transport of raw materials and the import/export of affordable food and manufactured goods would simply not be possible. There are now an estimated 100,000 ships on the seas and the fleet is growing fast as goods are ferried in vast quantities from Asia to consumers in Europe and USA. It is the availability, low cost and efficiency of maritime transport that has made possible the major shift towards industrial production in Asia and other emerging economies, which has in large part been responsible, in recent years, for dramatic improvements in global living standards.

In recent years, for international shipping the sustainability in a climate and an environmental perspective has become an issue of highest priority. Because other than economical issues there are some environmental issues which are resulted due to burning of more fuel onboard. The burning of diesel ultimately generates the energy required onboard ship. Each kilo-watt of energy saved onboard has a direct effect on the consumption of diesel and the total operating cost of the ship and sustainable business. Therefore ship operators will put higher pressure on ship owners to obtain fuel efficient ships.

These in turn will put pressure on ship yards to supply fuel efficient ships. (1)
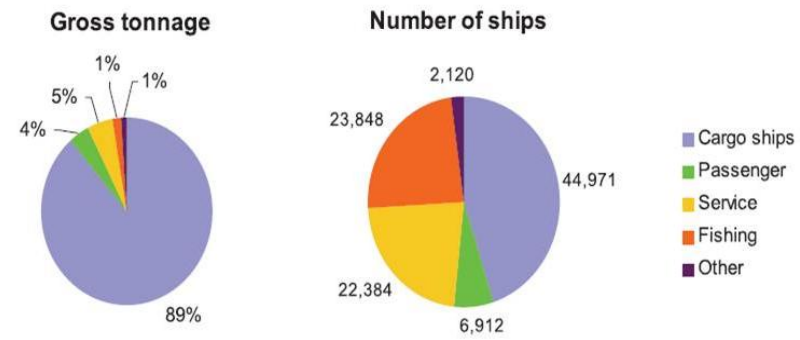

Total fleet: 100,243

Fig.1. 1 Total number of ships world wide

The shipping industry is facing ever greater challenges, especially regarding energy saving and the environment protection. Today the improvement in energy efficiency has become the most important aspect of shipping industry to achieve excellence in cost competitiveness. Energy cost is one of the major components that not only necessities the installation of energy efficient technology but also encourages energy efficient practices and methods to be used for pollution free eco-friendly shipping. The importance of shipping industry is very much traced to international transportation. It is generally acknowledged that more than 90 per cent of international trade is carried 
by sea. Over the past three decades, the activity in the shipping sector has grown on an average by $5 \%$ per year. During the last century due to increasing industrialization and the liberalization of national economies, shipping industry has seen a general trend of increases in total trade volume. The amount of goods actually loaded aboard ships has reached up to 10 billion tons. Like all industrial sectors, shipping industry has also witnessed the worst global recession in over seven decades and the sharpest decline in the volume of global merchandise trade. But the advances in technology have also made shipping an increasingly efficient and swift method of transport. Therefore the Energy Efficiency Design Index (EEDI) and Ship Energy Efficiency Management Plan (SEEMP) needs to be implemented strictly not only as required by law but also in order have sustainable shipping. (2)

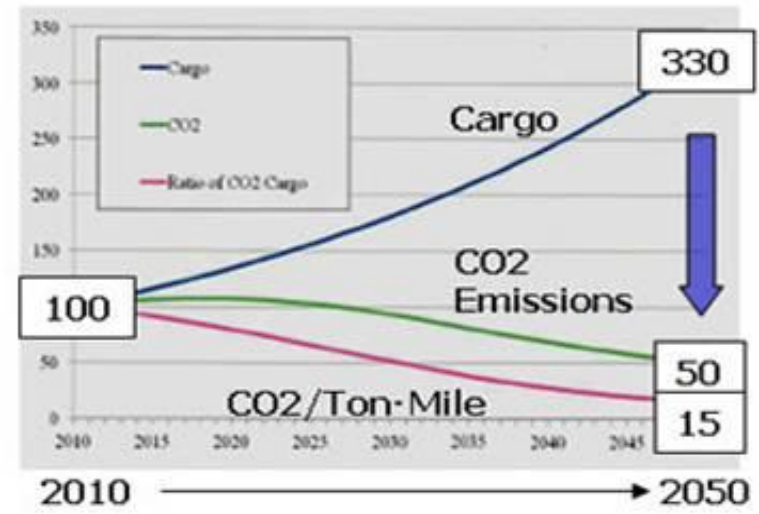

Fig. 1.2 Projected carbon emission from ship

This paper aims at presenting a method for calculating energy savings and reduction in $\mathrm{CO} 2$ emission that would result from installing VFDs on the sea water cooling pumps on ships. The ship main engine cooling system and navigation environment characteristics, including related marine equipment and ambient sea water temperature, etc. are taken into account. The process system that involves mechanical, instrument, and pump hydraulics, as well as electrical aspects of the drive is mathematically modeled so that the pump hydraulic formulas can be properly applied. Performance of the proposed method was validated through energy-savings analyses of an actual ship sea water cooling system. Effect of shipping routes on the energy savings was fully described. The analysis model developed in this paper can assist in performing the energy-saving calculations to permit checking of the economics of adjustable speed flow control for similar pumps on ships. (3)

\section{GREENHOUSE GAS EMISSION}

As ships get bigger, the pollution is getting worse. Therefore just 16 of the world's largest ships can produce as much lung-clogging sulphur pollution as all the world's cars (800 million cars) (14). The largest ships can each emit as much as 5,000 tons of sulphur in a year, the same as 50 million typical cars, each emitting an average of 100 grams of sulphur a year. As per IMO regulations the sulphur emission eventually must come down by limiting the sulfur content in fuel to 0.5 percent. It is generally estimated that $4 \%$ (1000 million tonnes) of the global greenhouse gases e.g. $\mathrm{CO}_{2}, \mathrm{SO}_{2}$ and $\mathrm{NO}_{2}$ emissions come from international shipping. It burns marine heavy fuel, or 'bunker fuel', which leaves behind a trail of potentially lethal chemicals e.g. Sulphur oxides and other air pollutants that have been linked to breathing problems, inflammation, cancer and heart disease. Due to global warming, there are number of changes in the environment. Polar ice caps are melting, sea water level is increasing and surrounding temperature is also increasing, heavy rains, acid rains, drought, heavy snowfall etc. are the common things happening around us. James Corbett is an authority on ship emissions calculates a worldwide death toll of about 64,000 a year and predicts the global figure will rise to 87,000 deaths a year due to GHG emissions. In addition if the emissions would not be regulated and sufficient measures are not taken then in near future we shall find global mean temperature rise by 2 degrees Celsius and few coastal cities and Iceland will get submerged under the water. Therefore by taking collective efforts, by 2020 we should be able to reduce consumption of fossil fuel and emission of GHG by $30-40 \%$.

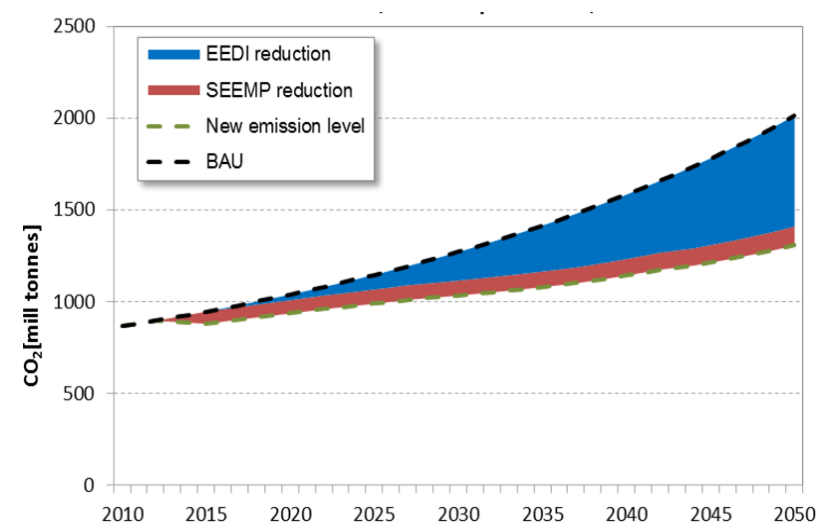

Fig.2.1 Proposed EEDI and SEEMP

The adoption of mandatory reduction measures for all ships by IMO from 2013 and onwards leads to significant emission reductions and also a striking cost saving for the shipping industry. By 2020, up to 180 million tonnes of annual $\mathrm{CO}_{2}$ reductions are estimated from the introduction of the EEDI for new ships and the SEEMP for all ships in operation, a figure that, by 2030, will increase to 390 million tonnes of $\mathrm{CO}_{2}$ annually. In other words, the reductions will in 2020 be between 9 and 16\%, and by 2030 between 17 and 25\% (15). The reduction measures will also result in a significant saving in fuel costs to the shipping industry, although these savings require deeper investments in more efficient ships and more sophisticated technologies than the business as usual scenario. The annual fuel cost saving estimates states a staggering figure of $\$ 34$ to 60 billion by 2020 , and even more astonishing $\$ 85-150$ billion by 2030 . (4)

\section{IMO REGULATIONS}

The growth in international maritime transport has resulted in generating substantial quantities of greenhouse gas (GHG) emissions e.g. $\mathrm{CO}_{2}$, SOx \& NOx. Globally shipping consumes around 300 million metric ton of fuel (Heavy Fuel Oil) annually. Cost of HFO is $\$ 600$ / metric 
ton (16). It has sulfur content. IMO tightened the Management Plan that has been made mandatory by IMO. regulations and restrictions on GHG emission. As IMO's MARPOL convention regulations pressurize to regulate GHG emission the issue is becoming stronger, not least as the global demand for sea transportation is expected to stay strong and possibly grow, with a corresponding increase in ship fuel consumption and emissions. Regulating the maritime industry to promote safety and security and prevention of pollution from ships worldwide has been the function of the International Maritime Organization since its inception in 1959. The amendments to MARPOL Annex VI, the regulations for the prevention of air pollution from ships, which entered into force on 1 January 2013, added a new chapter 4 to Annex VI on Regulations on energy efficiency for ships to make mandatory the Energy Efficiency Design Index (EEDI), for new ships, and the Ship Energy Efficiency Management Plan (SEEMP) for all ships. (5)

\begin{tabular}{|lc|}
\hline Type of Ship & gCO2/tonne-Km \\
Bulk Carrier & 20 \\
Small tanker (844 tonnes) & 5 \\
Large tanker (18,371 tonnes) & 5 \\
Deep-sea tanker (120,000 tonnes) & 11 \\
Small (solid) bulk vessel (1,720 tonnes) & 11 \\
Large (solid) bulk vessel (14,201 tonnes) & 7 \\
Container Vessel & \\
Small container vessel (2,500 tonnes) & 13.5 \\
Larger container vessel (20000 tonnes) & 11.5 \\
Average deep-sea container vessel & 8.4 \\
\hline
\end{tabular}

Fig. 3.1 Carbon emission from different ships

The international shipping industry is firmly committed under any new United Nations Climate Change Convention to playing its part in reducing emissions of $\mathrm{CO} 2$ and other Green House Gases. The COP15 conference held in Copenhagen at the end of 2009 aimed at getting a global agreement for reducing the amount of Green House Gases (GHG) worldwide. Regarding shipping a tangible effort was seen within the MARPOL Annex VI regulations at the 62nd session of the Marine Environmental Protection Committee (MEPC) in 2011. It is coming into effect for new and existing fleets. For new ships the Energy Efficiency Design Index (EEDI) will define the efficiency of the ship by design. Ships built between 2015 and 2019 will have to be $10 \%$ more efficient, ships built between 2020-2024 need to be $20 \%$ more efficient, and ships build after 2024-2050 need to be $30 \%$ more efficient. Meanwhile, for the existing tonnage the Ship Energy Efficiency Management Plan (SEEMP) will require that ship operators develop a plan to improve overall efficiency. $\mathrm{CO}_{2}$ is the most common GHG and the shipping industry today accounts for 3-4\% of total GHG emissions. It is estimated that this figure will grow rapidly if the shipping industry does not do anything to make the vessels more energy efficient.

The operational measures e.g. better speed management, throughout the course of a voyage, for controlling pumps is also expected to reduce fuel consumptions and is addressed in detail by the new Ship Energy Efficiency
This piece of legislation is significant because it is the first industry sector to introduce globally mandatory GHG reduction measures. By far the most commonly used flow controls in pump applications are throttle controls and bypass loops to control the temperature. As a consequence pumps are running at $100 \%$ loads continuously, even though the requirement would be actually about $40 \%$ in average. These traditional methods consume more power because they are analogous to operating a car with full speed and break is used to control the speed of car. So, they are not fuel efficient. Similarly even if we reduce speed and flow rate by $10 \%$, then power consumption can be reduced by $27 \%$ as per affinity laws. Due to duty cycle of pump and variable speed operation, the average will come around $40 \%$ (17).

\section{SEA WATER COOLING}

The ambient sea water temperature varies greatly as ships travel through different sea areas. The use of Variable frequency drives (VFDs) for shipboard applications is one of the most effective tools for energy savings. Significant energy benefit can be realized from VFDs driven sea water cooling systems because it reduces energy consumption and burning of fuel. This will obviously reduces the emission of GHG which further leads to the concept of green shipping. Cooling water pumps used onboard ships are especially dimensioned to have their rated capacity at a water temperature of $32^{\circ} \mathrm{C}$ or $38^{\circ} \mathrm{C}$. When operating in cooler seas, this means that unnecessary high volumes of cooling water are pumped through the systems, resulting in high cost of energy and wear of the mechanical equipment. Vessels used e.g. transporting fruit or food grains require very stable temperatures. In passing through climatic zones with changing temperature conditions, a marine frequency converter controlled cooling system will ensure constant storage room temperature. On board passenger and cruise vessels, considerable energy is used for ventilation and air conditioning. Day cycles and changing environmental temperatures mean the motor power requirement for systems of this kind will undergo large variations. With temperature control, only the required motor power will be used to maintain the desired temperature. (3)

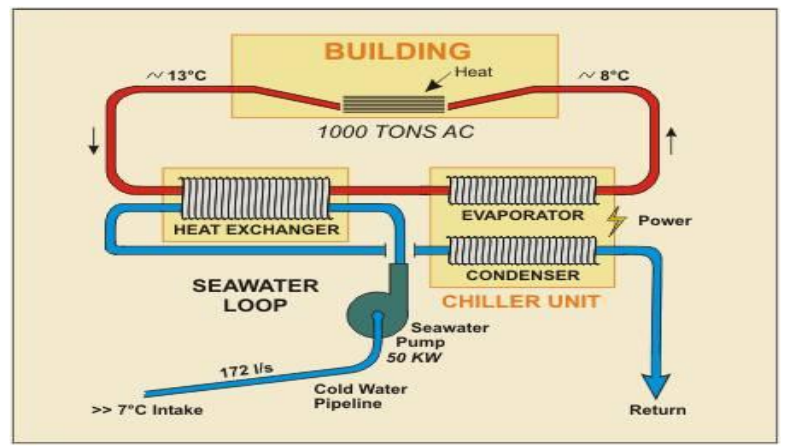

Fig. 4.1 Sea water cooling system

In case of the main cooling freshwater system, the heat is taken away from heat sources such as the main engine jacket, main engine air coolers, main engine lubricating oil etc. and this heat is transferred to the seawater in the 
central freshwater coolers and the seawater is sent overboard. Thus the sea acts as the heat sink. The seawater temperature however is not constant and it changes as the ship moves through various waters. The maximum seawater temperatures are experienced usually in the tropics and in the Persian Gulf. Therefore as the ship keeps moving the cooling system will experience the maximum seawater temperature for a short period of time; in other words, the maximum flow rates in the cooling water system will be for short spans. As the seawater temperature decreases, the flow rate in the cooling water system required to be reduced.

The sea water cooling system is controlled by centrifugal pumps and AC motors, the sea water cooling system is a key component on vessels. The system pumps ambient sea water into a circulating loop. This loop provides a heat exchange with the vessel's freshwater cooling system, which works to cool shipboard energy consumers that include the main engines, generators and auxiliary equipment. Once the sea water has taken heat from the fresh water, it is pumped back into the sea and cooler ambient sea water is drawn in and introduced to the system.

The sea water cooling system onboard vessels are designed to operate at $32^{\circ} \mathrm{C}$ sea water and $100 \%$ engine load. The auxiliary systems onboard run as if these temperature conditions are permanent. However the sea water temperature of the oceans is not $32^{\circ} \mathrm{C}$ all over the world. Actually there are only a few sea areas like tropical and equatorial regions where such conditions of high sea water are present. In these regions the average sea water temperature is around $30^{\circ} \mathrm{c}$. This means the sea water cooling system for almost $95 \%$ of operation times isr absorbing too much of energy. Therefore by installing proposed green technology for controlling flow rate of centrifugal pump, we can regulate the total energy consumption according to actual cooling demand and thereby saves fuel required by gensets. We can achieve more than $50 \%$ reduction in energy consumption for cooling water pumps e.g. centrifugal pumps at $28^{\circ} \mathrm{C}$ sea water temperature. The power consumption by the pump then reduced to four times compared to the speed reduction of the pump. Significant energy can be saved by the use of variable frequency drive for pumps to regulate flow of sea water. If we take trip from Shanghai to Singapore, the sea water temperature is around $24^{\circ} \mathrm{C}$. Therefore the pump flow control without VFD requires $100 \%$ speed and energy consumption of about $90 \mathrm{~kW}$. If VFD is used for sea water cooling system then pump speed required to be only $56 \%$ and energy consumption will reduce to only $22 \mathrm{~kW}$. After reaching Singapore the sea water temperature has reached $28^{\circ} \mathrm{C}$. At this temperature the pump speed will be $80 \%$ and energy consumption will be just $46 \mathrm{~kW}$. While voyage through Mediterranean Sea the sea water temperature will drop to around $20^{\circ} \mathrm{C}$, therefore pump speed can be reduced to $50 \%$ and energy consumption will be only $19 \mathrm{~kW}$. When arriving in Denmark the cumulative energy savings offered by the use of proposed Space Vector Pulse Width Modulated VFD during trip from Shanghai to Denmark will be around $52,000 \mathrm{~kW}$. This corresponds to $75 \%$ of energy saving as compared to traditional methods of flow control without speed reduction e.g. throttling, bypass or damper control etc. We can able to save about 80,000 \$ per year by using Smart and Green Technology with Intelligent Control for sea water cooling system onboard vessel. (6)

\section{BALLAST WATER MANAGEMENT}

Ballast is any material used to weight and/or balance an object. Ships have carried solid ballast, in the form of rocks, sand or metal, for thousands of years. Presently the ships use water as ballast. Shipping moves over $80 \%$ of the world's commodities and transfers approximately 3 to 5 billion tones of ballast water internationally each year. Water ballast is absolutely essential for safe and efficient operation of modern ships as it provides balance and stability to un-laden ships. It is much easier to ballast and de-ballast a ship with sea water and is therefore more efficient and economical than solid ballast. When a ship is empty of cargo, it fills in water ballast and when it loads cargo, the ballast water is discharged. (7)

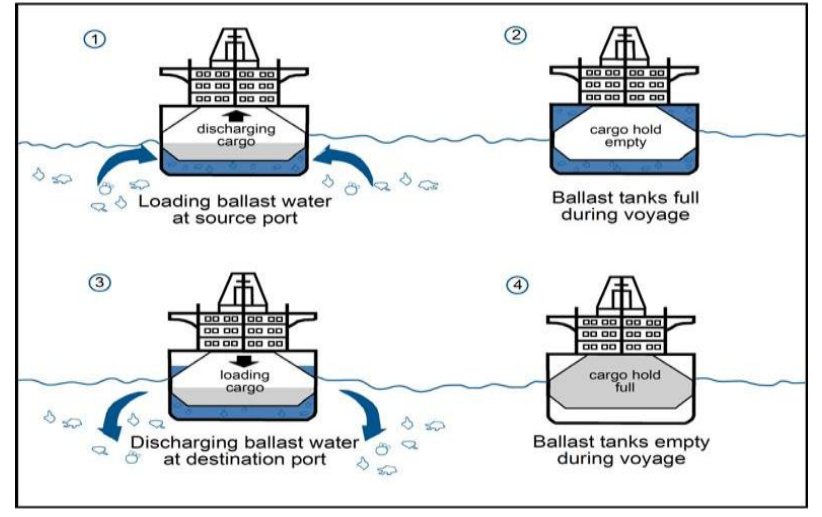

Fig. 5.1 Ballast and De-ballast during voyage

\section{MARINE FREQUENCY CONVERTER}

The traditional approach to flow control has used valves; which increase system pressure, inherently. Theoretically, it would be possible to operate at $50 \%$ flow with only $13 \%$ of the power required at $100 \%$ flow. As per affinity laws, the power consumption is proportional to cube root of speed. (i.e. $0.5 \times 0.5 \times 0.5=12.5) \quad(3)$. since the power requirements decrease to much greater extent than the reduction in flow, the potential exists for significant energy reduction at reduced flows. Centrifugal pumps are variable torque type loads and are generally sized to handle the peak flow requirements, which typically occur for very short periods of time. Consequently, the equipment would be operated at reduced flows most of the time. For this example, the system would be operated below $70 \%$ flow over $94 \%$ of the time. Thus, this sort of duty cycle could provide energy savings by adjustable speed operation of the pump. As a rule of thumb, the minimum flow rate is $25 \%$ of the BEP flow. For instance, if the BEP flow was $1000 \mathrm{GPM}$, then the minimum flow rate is $250 \mathrm{GPM}$.

The energy efficiency of the ship can be improved in number of ways e.g. design of hull, use of superconductivity, non conventional energy sources and 
use of power electronics technology for reducing speed and power etc. Here we have developed a simulation model using advanced power electronics technology for substantial saving of electrical energy and energy conservation onboard ship. As a result, we expect to see an improvement in the fuel consumption on ships by the use of variable frequency drive for sea water cooling and ballast water operation using centrifugal pumps. The proposed sea water cooling system using VFD consists of marine frequency converter, space vector pulse width modulation controller and temperature sensors. Centrifugal pumps are connected to marine frequency converters and temperature sensors are strategically installed in the cooling water system. All temperature sensors and frequency converters are connected to the master controller panel. From this controller panel, we can collect speed, temperature and energy consumption. This data is further used to determine actual energy savings, monitory savings and reduction of fuel consumption as well as reduction in emission of greenhouse gases. Thus VFD for sea water cooling system offers maximum energy saving and ensures safe and reliable operation, according to classification society's requirement. The proposed VFD for sea water cooling system can be easily installed without modification on the vessel safety functions and with minimum modification to the existing equipment. This is an advanced and user friendly system needed for protection of environment at sea. The proposed VFD controller is modular, failure proof system for new building vessels as well as for retrofits. This can also be used for fresh water cooling systems and engine room fans and blowers. It has a short payback time of 8 to 12 months depending on actual usage. (8)

Pumps and fans onboard vessels are often a vital application. If these are not working the vessel will not sail. On board vessels there are a lot of different pump applications; sea water cooling pumps, boiler feed pumps, HVAC pumps, bilge water pumps, fire pumps, waste water pumps and many other kinds. It is common for pump applications to be over-dimensioned. This is simply because the design criteria are set to meet the extreme conditions in which the vessel may operate. For example, the seawater temperature is generally dimensioned for above normal operating conditions. Onboard ships, around $80 \%$ of all pumps are centrifugal pumps serving multiple purposes. These pumps are used for ballast water operation, cargo operation, cooling systems (Main Cooling seawater pumps, Auxiliary Cooling seawater pumps, Main cooling freshwater pumps and Auxiliary cooling freshwater pumps), fire protection, fresh water, boiler water circulation, sewage system etc. At present, flow (volume) and pressure (head) control for these pumps can be achieved by using throttling or bypass methods, turbine driven control, pneumatic controller, hydraulic controller, trimming impellers, dampers and valves to adjust pump output. But there are some issues related to these traditional methods of controlling pump. (9)

All these existing traditional methods not only consume more energy but also give rise to burning of more fuel and emission of green house gases.

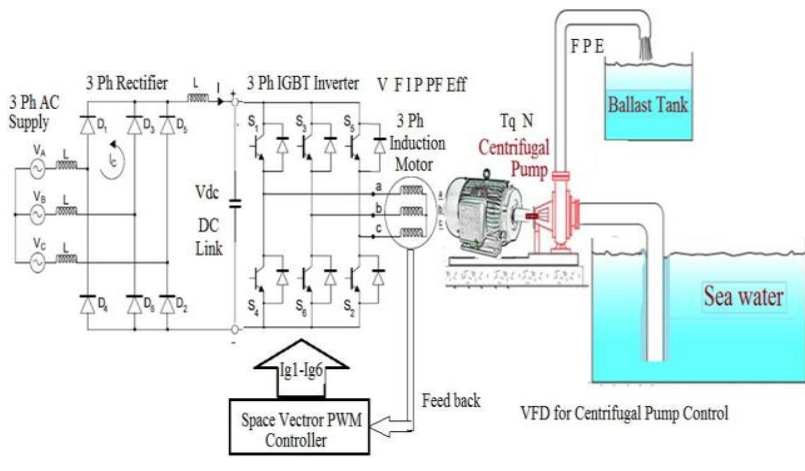

Fig. 6.1 Variable Frequency Drive for Controlling Pump

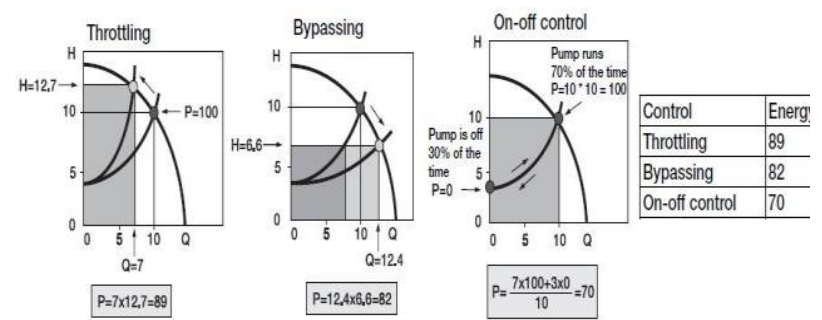

Fig. 6.2 Traditional methods of flow control

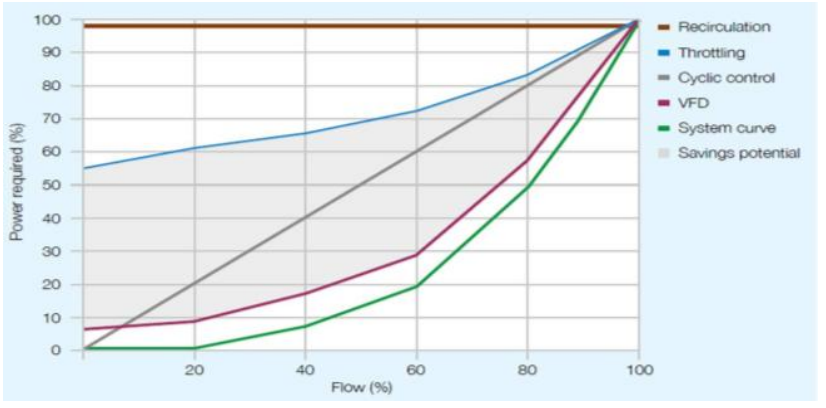

Fig. 6.3 Power savings by various methods

The drawback of using the control valves for variable flow and constant pressure is frequent valve failures that could lower pump efficiencies. Turbine-driven pumps have startup and capacity control difficulties. In some cases it can take $12 \mathrm{Hrs}$ to get steam generator and pump operating smoothly. This is wasted time and it becomes very expensive with a high value asset like an oil tanker. Hydraulic motors represent another common method of driving cargo pumps. The complexity of the equipment required especially the hose system, the risk of leaks and the problems that can occur when operating in cold weather conditions. The throttling and bypass devices are effective, but not energy efficient. Throttling and by-pass loops reduce the flow, but they do not reduce the power consumption of the motor. It requires burning of more fuel and in turn emits greenhouse gases e.g. Carbon Dioxide, Sulfur dioxide, Nitrogen Oxide, Carbon monoxide etc[34, 52]. The systems on existing ships are not energy efficient and have not been fully optimized for minimizing overall fuel consumption. Therefore these methods are not efficient, economical and environmental friendly. (9)

Centrifugal pumps are generally sized to operate at or near the best efficiency point at maximum flow. The maximum flow requirements, however, frequently occur for a very short period during the operating cycle with the result that 
some method of flow control is required. Although it is required for a ship to be able to operate in extreme cases and environments, every-day operations rarely come close to such conditions. While maximum allowed engine load is typically $75-90 \%$ of maximum, heat is always recovered from the system and seawater temperature very seldom reaches the design value. The key issue is to run pumps at efficient speeds as far as possible. If the cooling demand in the cooling circuit increases, more cooling water is needed, additional pumps can be switched on and run at an efficient speed. In a situation where all pumps are running at an efficient speed and cooling demand reaches the maximum, all pumps start to run at high speed. Therefore a lot of energy is easily saved by letting pumps and fans be controlled by a VFD, either standalone or with a pressure or temperature sensor loop control. Using a VFD to adjust the power demand to the operational conditions is the most effective method to optimize the shipboard systems. Let us assume that control valves 1,2 , and 3 require a maximum flow rate of 30, 10 and 25 GPM respectively and the required head in the system is 55 feet. As we discussed earlier, the maximum flow rate will be required relatively for a short span of time [tropical seas], say $5 \%$ of the total voyage. The pump for this case would be sized for 90 GPM and 55 feet of head, but the system will spend only $5 \%$ of the total voyage at this point and the system will not need such amount of cooling all the time. With a reduction in cooling requirements, in the main cooling freshwater system, the flow rate of the cooling freshwater is reduced and the VFD begins to crank the speed down from say 1800 to $1600 \mathrm{rpm}$. The old flow rate was $70 \mathrm{GPM}$ with the pump running at $1800 \mathrm{rpm}$ and the new flow rate is 50 GPM at $1600 \mathrm{rpm}$; this reduction in flow rate through the piping system reduces the pressures inside the system, though the piping was sized for a maximum pressure value corresponding to 70 GPM. With a reduction in speed, the pressure within the entire system reduces; this is where we get our benefit from using a VFD. The savings obtained keep magnifying with decreased flow rates cooling freshwater, with lower seawater temperatures encountered as a vessel sails to relatively colder waters such as the Mediterranean. The pump in this case could be operating at a far lower speed from $1800 \mathrm{rpm}$ to something in the range of $1500 \mathrm{rpm}$. We shall be calculating the various parameters such as the speed, power, head on the basis of affinity laws and from the calculations we shall be able to appreciate the savings obtained. The pump speed was reduced by $28 \%$, this reduced the system pressure by $47 \%$ but it gave a $62 \%$ reduction in power consumed. This is why VFDs are a vital component for shipboard centrifugal pumping systems. (10)

Rectifier Stage: A full-wave, solid-state rectifier converts three-phase $60 \mathrm{~Hz}$ power from a standard 208, 460, 575 or higher utility supply to either fixed or adjustable DC voltage.

Breaking Chopper: The DC output of rectifier is controlled by chopper i.e. DC to DC converter. This output DC acts as input to three faze Inverter.

Inverter Stage: IGBT/IGCT power transistors or thyristors switches the rectified DC on and off, and produce AC current and voltage waveform at the desired new frequency. The amount of distortion depends on the design of the inverter and filter. The output of inverter is variable voltage variable frequency with minimum harmonics.

Control System: It models a direct torque control (DTC) induction motor drive with space vector pulse width modulation. The particularity of this modified version is that the DTC is no longer based on hysteresis regulation that implies switching at variable frequency but on a fixed frequency PMW inverter. An electronic circuit receives feedback information from the driven motor and adjusts the output voltage or frequency to the selected values. Usually the output voltage is regulated to produce a constant ratio of voltage to frequency $(\mathrm{V} / \mathrm{Hz})$. Controllers may incorporate many complex control functions. Inverters use Space Vector Pulse Width Modulation (SVPWM) because the output current waveform closely approximates a sine wave. IGBT switches DC voltage at high speed, producing a series of short-duration pulses of constant amplitude. Output voltage is varied by changing the width and polarity of the switched pulses. Output frequency is adjusted by changing the switching cycle time. The resulting current in an inductive motor simulates a sine wave of the desired output frequency. The highspeed switching of a SVPWM inverter results in less waveform distortion and therefore, lowers harmonic losses. Low voltage variable speed drives offer powerful and accurate performance for any application in powers of 0.55 up to $5600 \mathrm{~kW}$

Induction Motors: Three phase high efficiency induction motors offer a comprehensive range up to $18000 \mathrm{~kW}$ and are very reliable. These machines are commonly used onboard ship as prime movers for centrifugal pumps. IMs consume about $35 \%$ of the total ship energy consumption. The simplicity of these machines allows them to be perfectly engineered according to requirements for application areas that include special and hazardous environments.

Centrifugal Pump: The load for the IM is variable torque type centrifugal pump. In the simulated model $500 \mathrm{HP}$ Pump with maximum of $3000 \mathrm{~m}^{3} / \mathrm{hr}$ flow rate is controlled using SVPWM controlled Variable Speed Drive. Thus we can adjust flow rate of ballast water system using VFD and reduce the consumption of energy and fuel. (11)

\section{AFFINITY LAWS}

The affinity laws for specific pumps are, the volume (Flow) is proportional to speed. The pressure (head) is proportional to square of the speed and the power absorbed is proportional to cube of the speed [2]. The affinity curve shows that at $100 \%$ rated speed and a fully loaded pump, the horsepower consumption is maximum. If a $30 \%$ reduction in speed is allowable by the system process requirements then the pump may be driven at $70 \%$ of the maximum motor RPM with a nominal power consumption of $34.0 \%$ of the full load, full speed consumption. i.e. Power consumed $=(0.7)^{3}=0.343=$ $34.3 \%$. For $60 \mathrm{~Hz} / 2$ Pole IM, If we reduce $1 \mathrm{~Hz}$ 
frequency then Speed will reduce by 60 RPM i.e. $10 \%$ reduction in speed can reduce power consumption up to $.9 \times .9 x .9=72.9 \%$ i.e. Saving $=27.1 \%$ power. Thus VFD is useful in energy saving because it reduces the motor speed as demand decreases and saves fuel and energy. The pump and driving motor must then develop enough torque to actually move the fluid. (12)
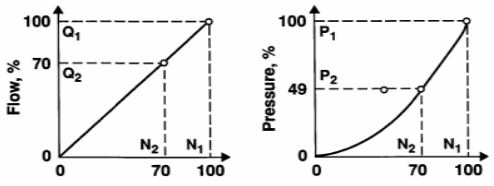

$$
\begin{aligned}
\frac{Q_{2}}{Q_{1}}=\frac{N_{2}}{N_{1}} \quad \text { Spood, \% } & \\
& \text { Flow } \propto \text { Speed }
\end{aligned}
$$

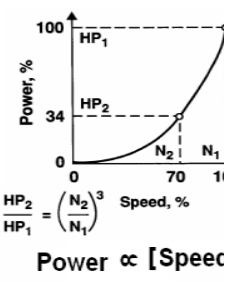

Fig.7.1 Affinity laws for pump

\section{SIMULATION USING MATALB}

It models a direct torque control (DTC) induction motor drive with a braking chopper for a 200HP AC motor. The induction motor is fed by a SVPWM voltage source inverter using IGBT. The speed control loop uses a proportional-integral controller to produce the flux and torque references for the DTC block. The DTC block computes the motor torque and flux estimates and compares them to their respective reference. The comparators outputs are then used by an optimal switching table which generates the inverter switching pulses. Motor current, speed, and torque signals are available at the output.

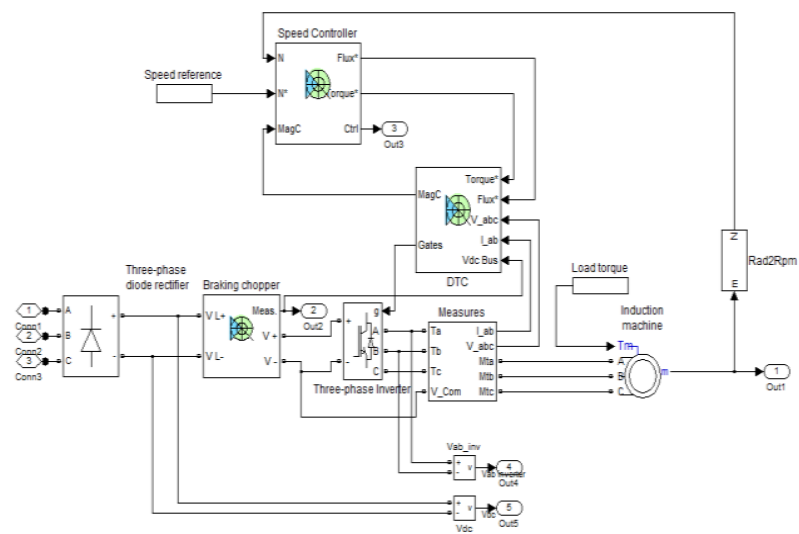

Fig. 7.2 DTC based VFD control for 3 phases IM

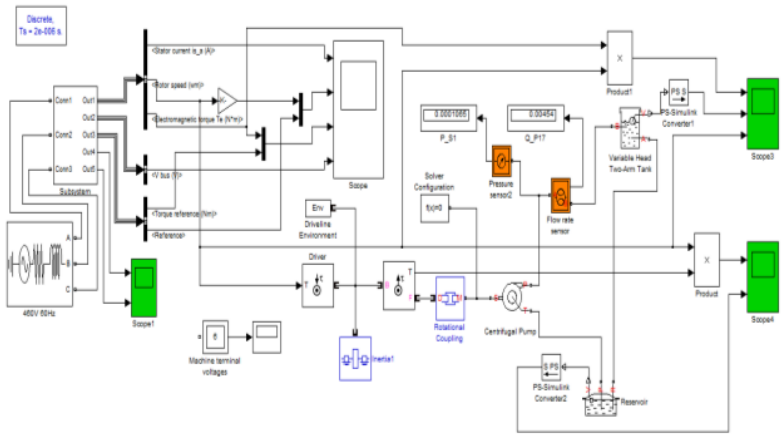

Fig. 7.3 VFD Controlled Centrifugal Pump
After the simulation, we can observe the motor stator current, the rotor speed, the electromagnetic torque and the DC bus voltage on the scope. The speed set point and the torque set point are also shown. In order to control centrifugal pump using VFD controlled three phase IM, pump system is also modeled and simulated for $3000 \mathrm{~m}^{3} / \mathrm{Hr}$ flow rate. (13)

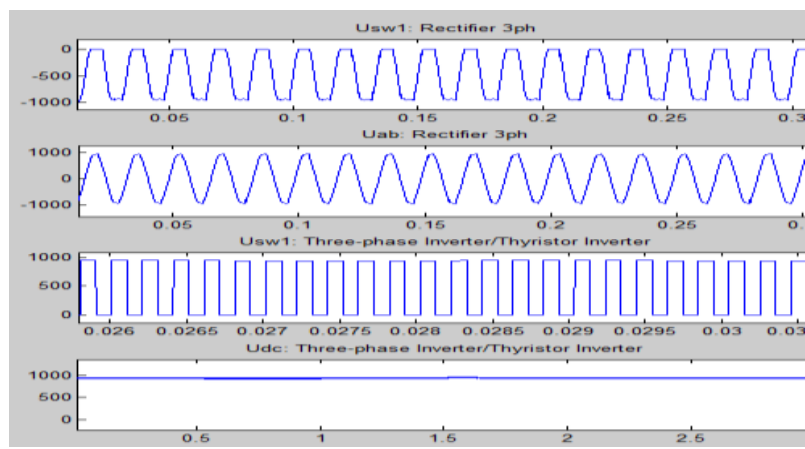

Fig. 7.4 Rectifier and Inverter Waveforms

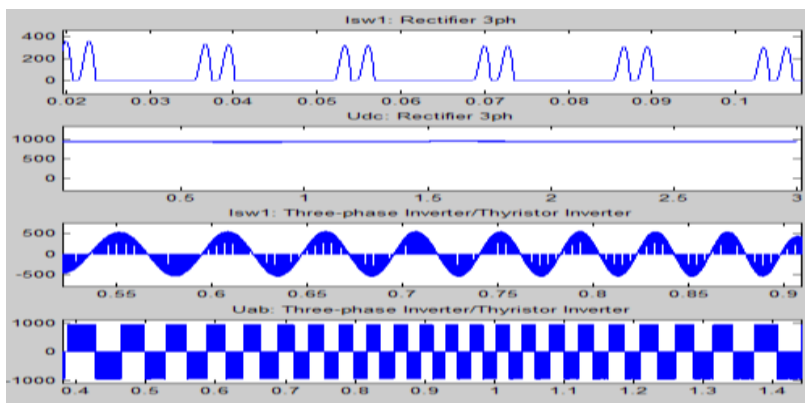

Fig. 7.5 PWM and AC o/p waveforms

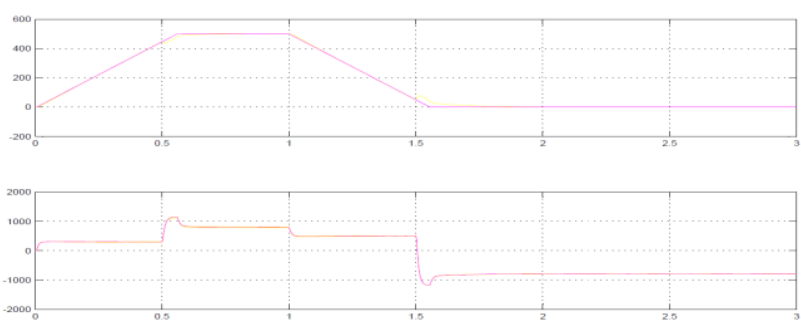

Fig. 7.6 speed and torque response

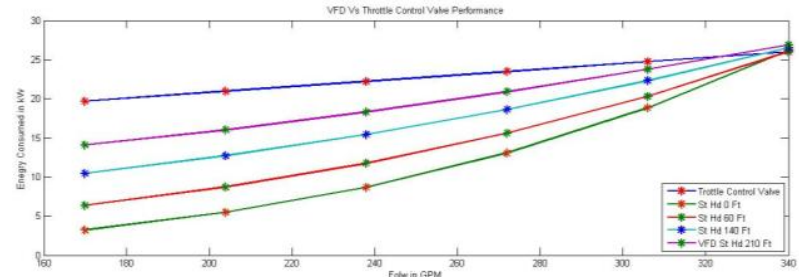

Fig. 7.7 Energy consumption

\section{EXPERIMENTATION}

The VFD controlled centrifugal pump with 400 HP power, $50 \mathrm{~Hz}, 380 \mathrm{~V}$ AC nominal voltage, 2 poles and $2900 \mathrm{RPM}$ nominal speed squirrel cage three phase induction motor of $500 \mathrm{HP}$ is used for validation of results. VFD efficiency is $98 \%$, IM efficiency is $90 \%$ and Pump efficiency is $80 \%$. Maximum head can be 30 meter. Pressure sensor is a 0-10 Bar ranged pressure switch in constant speed control 
strategy and an analog piezoelectric pressure transmitter with $24 \mathrm{~V} \mathrm{DC}$ feed voltage and 4-20 mA o/p current in variable speed control strategy.

Table1. VFD \& Throttling valve comparison, energy in $\mathrm{kW}$

\begin{tabular}{|l|l|l|l|l|l|l|}
\hline Flow & $\%$ & Throttled & \multicolumn{4}{|l|}{ VFD Static head in feet } \\
\hline GPM & Flow & Valve & $0 \mathrm{Ft}$ & $60 \mathrm{Ft}$ & $140 \mathrm{ft}$ & $210 \mathrm{Ft}$ \\
\hline 170 & 50 & 19.7 & 3.2 & 6.35 & 10.44 & 14.08 \\
\hline 204 & 60 & 20.95 & 5.46 & 8.7 & 12.7 & 16.02 \\
\hline 238 & 70 & 22.21 & 8.68 & 11.75 & 15.42 & 18.3 \\
\hline 272 & 80 & 23.47 & 13.06 & 15.58 & 18.61 & 20.9 \\
\hline 306 & 90 & 24.73 & 18.83 & 20.31 & 22.31 & 23.77 \\
\hline 340 & 100 & 25.99 & 26.19 & 26.02 & 26.52 & 26.89 \\
\hline
\end{tabular}

Table2. Percentage energy saved

\begin{tabular}{|l|l|l|l|l|}
\hline Sr. & $0 \mathrm{Ft}$ & $60 \mathrm{Ft}$ & $140 \mathrm{Ft}$ & $210 \mathrm{Ft}$ \\
\hline 1 & 83.75635 & 67.7665 & 47.00508 & 28.52792 \\
\hline 2 & 73.93795 & 58.47255 & 39.37947 & 23.53222 \\
\hline 3 & 60.91851 & 47.0959 & 30.57181 & 17.60468 \\
\hline 4 & 44.3545 & 33.61738 & 20.70729 & 10.95015 \\
\hline 5 & 23.85766 & 17.87303 & 9.785685 & 3.881925 \\
\hline
\end{tabular}

Table3. Total cost saved in a year

\begin{tabular}{|l|l|l|l|l|}
\hline Sr. & \multicolumn{4}{|c|}{ Cost saved /year @ $0.06 \$$ for $8 \mathrm{Hrs} / 250$ days } \\
\hline $\begin{array}{l}\text { Head in } \\
\text { Feet }\end{array}$ & $0 \mathrm{Ft}$ & $60 \mathrm{Ft}$ & $140 \mathrm{Ft}$ & $210 \mathrm{Ft}$ \\
\hline 1 & 1485 & 1201.5 & 833.4 & 505.8 \\
\hline 2 & 1394.1 & 1102.5 & 742.5 & 443.7 \\
\hline 3 & 1217.7 & 941.4 & 611.1 & 351.9 \\
\hline 4 & 936.9 & 710.1 & 437.4 & 231.3 \\
\hline 5 & 531 & 397.8 & 217.8 & 86.4 \\
\hline
\end{tabular}

Table4. Variation of speed and energy saving

\begin{tabular}{|l|l|l|l|}
\hline Sr. & SPEED & VOLUME OR FLOW & I/P HP \\
\hline 1 & $100 \%$ & $100 \%$ & $100 \%$ \\
\hline 2 & $90 \%$ & $90 \%$ & $73 \%$ \\
\hline 3 & $80 \%$ & $80 \%$ & $51 \%$ \\
\hline 4 & $70 \%$ & $70 \%$ & $34 \%$ \\
\hline 5 & $60 \%$ & $60 \%$ & $22 \%$ \\
\hline
\end{tabular}

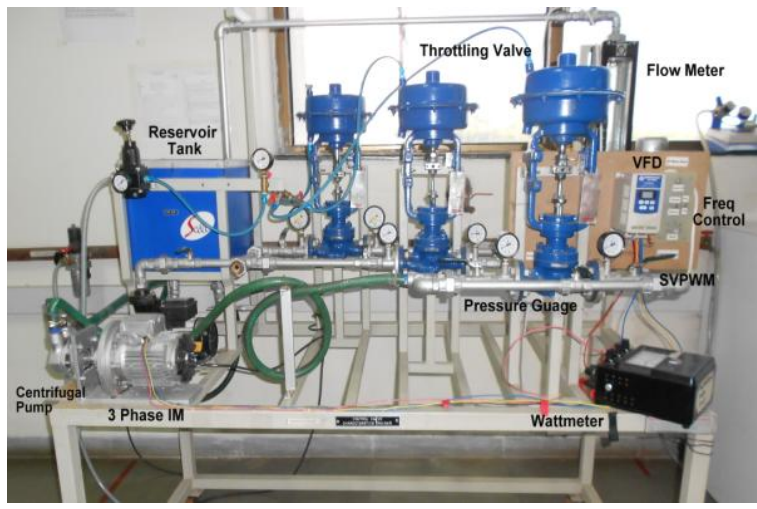

Fig.8.1 Experimental setup for controlling pump with VFD
Table5. Reduction in $\mathrm{CO}_{2}$ emission and cost savings

\begin{tabular}{|c|c|c|}
\hline Bulk Carrier & $2 \times 100 \%$ & Energy Cost $\$ 1 \mathrm{kw} / \mathrm{h}$ \\
\hline $\begin{array}{c}\text { Sea Water } \\
\text { Cooling System }\end{array}$ & \multicolumn{2}{|c|}{ INDIAN OCEAN } \\
\hline $\begin{array}{c}\text { Vessel Size in } \\
\text { KDWT }\end{array}$ & \multicolumn{2}{|c|}{ SHANGHAI to HAMBURG } \\
\hline & $\mathrm{Co}_{2}$ Tons & Cost Saved \\
\hline 10 to 35 & 5.9 & 128,903 \\
\hline 35 to 59 & 6.3 & 146,125 \\
\hline 60 to 80 & 6.8 & 171,912 \\
\hline 80 to 100 & 7.6 & 214,869 \\
\hline
\end{tabular}

\section{Super Eco-Ship}

A) Major benefits of installing a VFD

VFD offers soft starting feature. It has no big starting currents causing disturbance on the network, no process disturbance due to voltage drops, no trips of other electrical devices connected to same bus, no excessive thermal mechanical stress on the motor, longer lifetime of the motor, immediate start-up without warming-up delays (e.g. steam turbines), controlled and smooth start-up, accurate process control for flow, mechanical weariness of piping is minimum, risk of cavitation in the pump is minimum, passenger comfort (in air conditioning application), energy efficiency, reliability/ technical improvement, environmental compliancy.

\section{B) VFD Applications:}

Other than pumps VFD can also be used onboard ship for control of HVAC systems which saves energy. Traditionally hydraulic systems are used in passenger vessels for heating, ventilation and air-conditioning for winch the energy consumption is very high. VFD also can be used for space reduction, for shaft generator (shaft generator is used to generate electrical power for ship's network \& propulsion), used in electro-mechanical drive systems to control AC motor speed and torque by varying motor input frequency and voltage.

\section{C) System specifications:}

VFD 96kW / 240kW, Voltage: 380-480 V AC, Shaft power: $45 \mathrm{~kW}$, Nom. current: 90 A, Ambient conditions: Suitable for $50^{\circ} \mathrm{C}$ engine room, S.W. Cooling Pumps of $2500 \mathrm{~m}^{\wedge} 3 / \mathrm{Hr}$ flow rate \& Head 150 meter, fuel burning and emission $2.9 \mathrm{~kg} \mathrm{Co} 2 /$ litre. Provides more than $30 \%$ fuel savings.

\section{SIMULATION RESULTS}

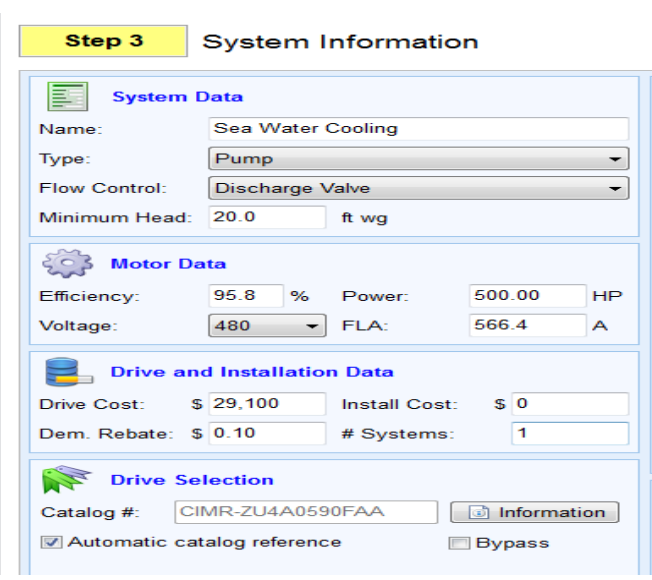

Fig. 9.1 Pump Selection 


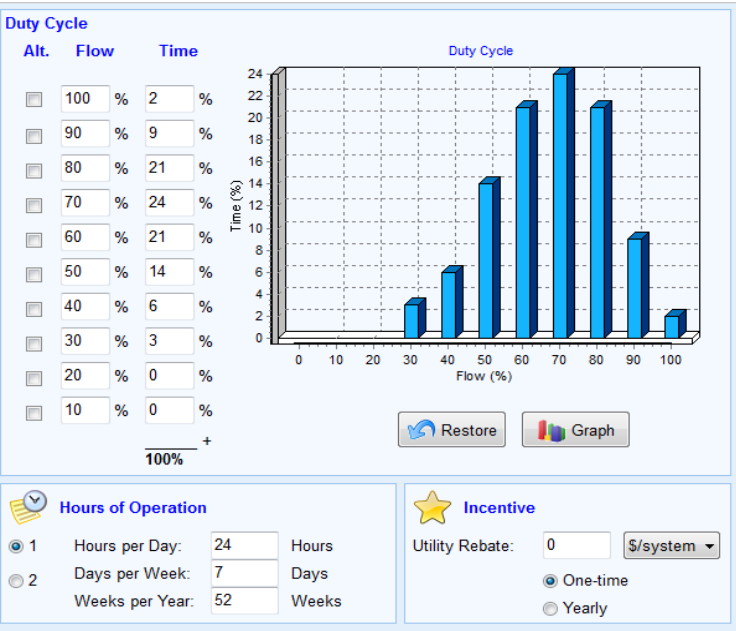

Fig. 9.2 Duty Cycle for operating pump

\section{Step 4 Energy Estimation}

\begin{tabular}{|lr|}
\hline Project Identification: & Energy Savings \\
\hline System & Energy Usage \\
Present System: & $2,808,737 \mathrm{kWh}$ \\
Drive System: & $1,406,926 \mathrm{kWh}$ \\
Energy Saved: & $1,401,810 \mathrm{kWh}$ \\
\hline Project Cost/Rebates & \\
\hline Total Equipment Cost: & $\$ 29,100$ \\
Total Installation Cost: & $\$ 0$ \\
Total Utility Rebates: & $\$ 6$ \\
Total Demand Savings: & $\$ 374$ \\
\hline
\end{tabular}

Fig. 9.3 Total energy savings

\begin{tabular}{|lr|}
\hline \multicolumn{1}{|l|}{ System } & Weight Units: English \\
\hline $\begin{array}{l}\text { Present System: } \\
\text { Drive System: }\end{array}$ & $1,029.40$ Ton(s) \\
CO2 Savings: & 515.64 Ton(s) \\
\cline { 2 - 2 } & 513.76 Ton(s) \\
\hline \begin{tabular}{|l|} 
Predicted Savings \\
Yearly Energy Savings:
\end{tabular} \\
\hline Payback Estimation & All Systems \\
\hline Simple System Payback/ROI: $\mathbf{0 . 2 0 7}$ Years \\
\hline
\end{tabular}

Fig. $9.4 \mathrm{CO}_{2}$ reduction

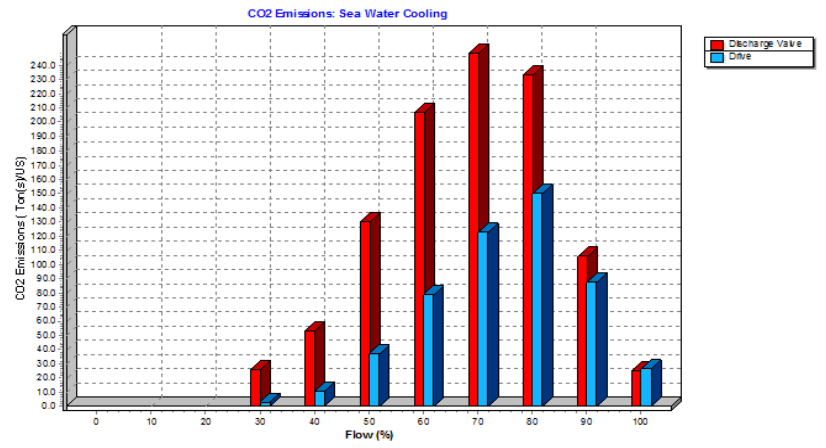

Fig. 9.5 Comparison of $\mathrm{CO}_{2}$ reduction

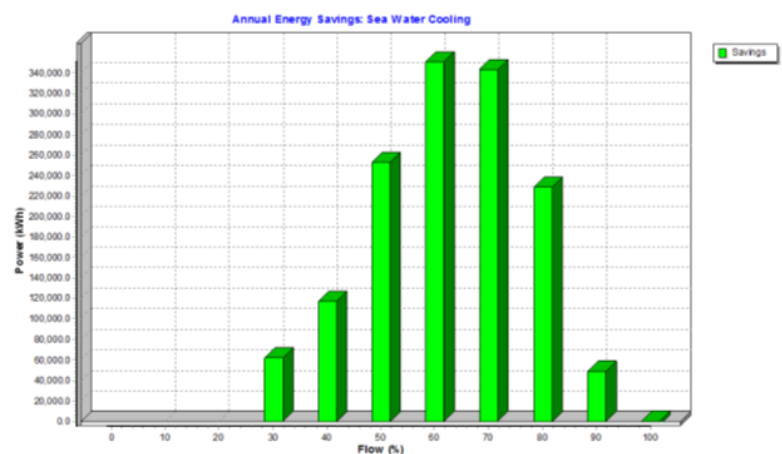

Fig. 9.6 Energy savings per year.

\section{CONCLUSIONS}

The validation of the proposed VFD is based on regulations suggested by MARPOL Chapter-4, Annex-VI. It can be done as per the standards set by various classification societies e.g. DNV (Det Norske Veritas), LR (Lloyd's Register of Shipping), ABS (American Bureau of Shipping), RINA (Registro Italiano Navale), BV (Bureau Veritas), GL (Germanischer Lloyd), Class NK, SCI etc. The proposed VFD complies with the norms of marine approved frequency converter. This VFD can be used for sea water cooling and for ballast operation onboard ship. The Major benefits from installing a VFD are:

Soft starting - no big starting currents causing disturbance on the network, no process disturbance due to voltage drops; no trips of other electrical devices connected to same bus, no excessive thermal mechanical stress on the motor; longer lifetime of the motor, immediate start-up without warming-up delays (e.g. steam turbines), controlled and smooth start-up, accurate process control flow based on production need, mechanical wear and tear of piping is minimum, risk of cavitations in the pump is minimum, passenger comfort (in air conditioning application), energy efficiency, reduced fuel consumption, reduction in green house gas emission, reliability/technical improvement, environment friendly, Smart, Green and Intelligent Technology.

\section{ACKNOWLEDGEMENTS}

The Author of the paper is very much thankful to top management, authorities, senior faculty and colleagues in Tolani Maritime Institute, Induri, Pune, for their continuous support and encouragement given during the process of research.

\section{REFERENCES}

[1] Buhaug, Ø., Corbett, J.J., Endresen, Ø., Eyring, V., Faber, J., Hanayama, S., Lee, D.S., Lee, D., Lindstad, H., Markowska, A.Z., Mjelde, A., Nelissen, D., Nilsen, J., Pålsson, C., Winebrake, J.J., Wu, W., Yoshida, K., Second IMO GHG Study 2009, International Maritime Organization (IMO) London, UK, April 2009, ed. anonymous. 2009. 240

[2] Hughes, Edmund, A new chapter for MARPOL Annex VI requirements for technical and operational measures to improve the energy efficiency of international shipping, ed. anonymous.

[3] ABB, ABB Energy Efficiency solutions Simple steps to reduce fuel consumption, ed. anonymous. 2015.

[4] Lene Espersen, Jan Fritz Hansen, Michael Prehn, Green Ship of the Future. Green Ship Magazine, ed. anonymous. 
[5] ECTA, Cefic and, Guidelines for Measuring and Managing CO2 Emission from Freight Transport Operations, ed. anonymous. 2011.

[6] COLFAX, ALLWEILER and IMO, China Navigation New cargo vessels carry added green advantage - sea water cooling systems designed to save energy. COMMERCIAL MARINE SMART TECHNOLOGY CM-1000 CASE STUDY, ed. anonymous. 2013.

[7] IMO, GloBallast Partnership, ed. anonymous. 2013.

[8] Simens, The guide of Marine Frequency Converters. Marine Equipments , ed. anonymous.

[9] $\mathrm{ABB}, \mathrm{ABB}$ drives Using variable speed drives (VSDs) in pump applications. Application guide No. 2 - Using variable speed drives (VSDs) in pump applications, ed. anonymous. 2006. 36.

[10] Alfredo Mu noz-Garc'ra, Thomas A. Lipo, Fellow, IEEE, and Donald W. Novotny, Fellow, IEEE, A New Induction Motor V/f Control Method Capable of High-Performance Regulation at Low Speeds. IEEE TRANSACTIONS ON INDUSTRY APPLICATIONS, VOL. 34, NO. 4, JULY/AUGUST 1998, 1998: p. 813-821

[11] Radan, Damir, Power electronic converters for ship propulsion electric motors. Marine CyberneticsEnergy Management Systems, Part of the NTNU project All Electric Ship, Department of Marine Technology, NTNU, 2004.

[12] Tole Sutikno, Nik Rumzi Nik Idris \& Auzani Jidin, A New Fixed Switching Frequency Direct Torque Controlled PMSM Drives with Low Ripple in Flux and Torque. ITB J. Eng. Sci., 2011. 43(3): p. 173-190.

[13] Carrier, OPERATION AND APPLICATION OF VARIABLE FREQUENCY DRIVE (VFD) TECHNOLOGY. Carrier Corporation Syracuse, New York, October 2005, ed. anonymous. 2005.

[14] Mail Online, $21^{\text {st }}$ November 2009. How 16 ships create as much pollution as all the cars in the world by Fred Pearce.

[15] IMO Technical Co-operation Building Capacities in Developing Countries to address GHG emissions from Ships.

[16] Alf Kare Adnanes, Energy efficiency in marine vessels.

[17] Jan-Erik Räsänen and Eric W Schreiber, ABB Marine \& Cranes Service, 2012/04/24, Using Variable Frequency Drives (VFD) To Save Energy and Reduce Emissions in New Building and Existing Ships.

\section{BIOGRAPHIES}

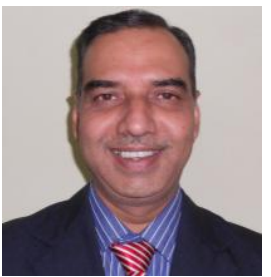

Mr. Sanjay Dabadgaonkar, Associate Professor in Department of Electrical and Electronics at Tolani Maritime Institute, Induri, Pune. Total Teaching experience of about 25 years. Worked as a Head of Dept. in Electronics and Telecommunication at College of Engineering under, Dr. B A M U Auranbabad. Published 10 Papers in International / National Journals and Presented more than 50 papers in Inter-national / National Conferences. Attended several workshops, honored with a best teaching faculty award, Member of University LIC and Chairman / Head during NBA \& AICTE Visit in COEO, Organised Two National Level conferences. Fellow member of IETE, ISTE, IE. Research in Simulation of Power Electronic systems is in progress.

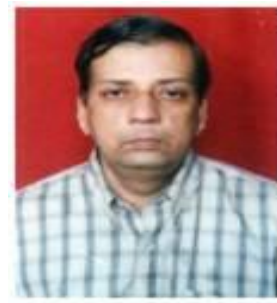

Dr. Asim Kumar Sen, Presently Working as a Principal and Professor, Saint Francis Institute of Technology, Borivali, Mumbai. Completed Ph.D. In 1995 from IIT Kharagpur. Fellow IE (India), LM of International Society for Reliability Engineers (India Chapter), LMISTE,
Fellow of IETE, Honorary Council Member of Flash India Management Senate, Mumbai, Referee of the Journals published by A.M.S.E, France, Chartered Engineer, LM of Indian Nuclear Society, Experienced faculty in the field of Electronics, Instrumentation and control, Digital Signal Processing, Industrial Engineering and Management. Having administrative experience as a Principal for more than 12 years. More than 60 Publications in International / National Journals and Conference Proceedings. Guided several Projects and $\mathrm{Ph}$. D. Thesis and in the panel of Supervisor for different Universities for guiding research related activities.

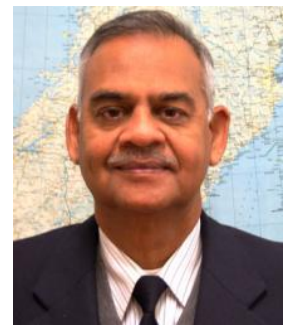

Dr. Rajendra Prasad, Presently member of faculty in the Marine Engineering Area at the Tolani Maritime Institute, Induri, Talegaon Dabhade, Pune. Total teaching experience of over thirty years. Before taking the present assignment worked as Assistant Professor at the World Maritime University in Sweden. A marine engineer by profession worked as chief engineer on board different types of ships and later ashore as a superintendent and then as General Manager in-charge of the fleet of Bulk Carriers of the Shipping Corporation of India Ltd. Before joining the World Maritime University headed the Maritime Training Institute of the Shipping Corporation of India Ltd. While at the World Maritime University was involved in number of EU funded research projects, presented papers at eleven international conferences as well as wrote papers for publication in number of international journals. Fellow of the Institute of Marine Engineers (India) and member of the International Maritime Lecturers Association. 